Cadernos de Clio, Curitiba, n. ${ }^{\circ}$ 4, 2013

\title{
“LÁ E DE VOLTA OUTRA VEZ”: O MEDIEVO NA OBRA DE J.R.R. TOLKIEN
}

Andrey Augusto Ribeiro dos Santos ${ }^{1}$

RESUMO: O presente artigo tem como intenção demonstrar os primeiros passos da minha pesquisa monográfica, na qual pretendo me debruçar sobre os aspectos medievais presentes nas obras do autor J.R.R. Tolkien. Devido a todo o apelo que estas possuem frente ao grande público, consideramos que se mostram como objetos válidos de estudo das representações da Idade Média no mundo contemporâneo. Assim, apresentarei meus questionamentos e avanços na pesquisa até o momento, com a intenção de demonstrar como o autor, sendo um homem do século $\mathrm{XX}$, poderia ter utilizado o Medievo como refúgio à dura realidade de sua época. Além de tentar explicar o que o grande sucesso destas obras pode nos dizer sobre a relação entre o grande público e sua representação de Idade Média.

Palavras-chave: Idade Média e Contemporaneidade; Literatura e História; Meios de entretenimento e História.

\section{Introdução}

A Idade Média é um período histórico ainda hoje, pelo menos frente ao grande público, muito representado pelos dois clichês comumente associados a esta época e que especialistas na área tem provado há muito tempo não serem verdadeiros. Por um lado, a imagem de Idade Média

\footnotetext{
${ }^{1}$ Graduando do $7^{\circ}$ período em História e Bolsista PET História - UFS. Integrante do Vivarium - Laboratório de Estudos da Antiguidade e do Medievo (Núcleo Nordeste). É orientado pelo Prof. Dr. Bruno Gonçalves Alvaro, do Departamento de História da Universidade Federal de Sergipe e pesquisador do Vivarium Laboratório de Estudos da Antiguidade e do Medievo (Núcleo Nordeste). E-mail para contato: andrey_long@hotmail.com.
} 
Cadernos de Clio, Curitiba, n. ${ }^{\circ}$ 4, 2013

violenta e sombria, por outro a romântica. (ALVARO, B.G.; PRATA, R.C., 2012, p.10)

Um preconceito que perdurou por muito tempo baseado no que foi construído pelo Renascentismo e difundido pelo Iluminismo. Ou seja, um medievo de atraso, escuridão, violência e dominação religiosa. Podemos atestar esta visão, por exemplo, na alcunha "Idade das Trevas” ou quando alguém taxa alguma atitude ultrapassada ou violenta de medieval. A outra representação associada a este período foi a difundida pelos românticos do século XIX. Aquela de uma Idade Média fantasiosa e povoada por cavaleiros honrosos em armaduras reluzentes, belos bosques e donzelas inocentes e apaixonadas.

É justamente a essas duas construções que os meios de entretenimento, área onde podemos perceber bem a predominância destas duas visões, sempre recorrerão, conseguindo, na maioria das vezes, uma fonte rentável de lucro. Desta maneira, mesmo com os medievalistas tentando mostrar que o medievo não foi o que é representado nos dois clichês apresentados acima, esta é a Idade Média que costumamos ver em filmes, músicas, séries de TV, jogos e livros de sucesso que tratam sobre o tema para o grande público. Entre os produtos de sucesso em destaque no momento, um dos que mais chama atenção, é o conjunto de obras que narra a estória da Terra Média.

Escrita pelo autor John Ronald Reuel Tolkien, ou J.R.R. Tolkien, esta narrativa épica, cujos tons nos remetem ao medievo, tem em $\mathrm{O} \mathrm{Se}$ nhor dos Anéis a sua mais conhecida série. Sua adaptação ao cinema em uma trilogia de filmes dirigida por Peter Jackson foi um grande sucesso chegando a igualar o número de Oscar de filmes famosos como Titanic. A 
obra chama a atenção por estar em alta desde o lançamento dos livros, há 58 anos, e por ter reunido uma grande legião de fãs pelo mundo todo.

Devido à amplitude do seu sucesso ela tem grande influência em outros ramos de entretenimento, além de um grande apelo perante o público. Exemplo disto foi o lançamento em 2012 de O Hobbit - Uma Jornada Inesperada, primeiro filme de uma trilogia que adaptará mais uma obra de Tolkien e que teve grande impacto junto ao público antes e depois da sua estreia. Mais uma vez, a Terra Média encontra-se nas pautas do momento e observamos, por sua vez, novamente a possibilidade de inferir-se que, também, nesta obra tolkiana a Idade Média serve como pano de fundo para sua construção, unida a várias outras influências.

Levando em consideração toda uma reconhecível aproximação representativa do mundo medieval nestas obras e o seu sucesso, é que pensei em iniciar esta pesquisa sobre o impacto que "O Senhor dos Anéis” teve, e ainda tem, sobre o ramo do entretenimento e o público em geral e de como ele revela o modo que um homem do séc. XX lida com o Medievo. Para isso é preciso, antes de tudo, que estudemos a vida do autor que construiu esta obra, para que possamos, assim, começar a tentar definir o motivo ou motivos para sua escolha por uma ambientação medieval nas suas obras.

\section{O autor}

Segundo Michael White na obra intitulada J.R.R. Tolkien, o senhor da fantasia, John Ronald Reuel Tolkien nasceu na cidade de Bloemfontein, África do Sul em 1892. Seu pai, Arthur Reuel Tolkien, trabalhava para o Lloyds Bank, e atraído pelas riquezas minerais sul-africanas conseguiu 
Cadernos de Clio, Curitiba, n. ${ }^{\circ}$ 4, 2013

ser transferido para lá, onde vem a se casar com Mabel Suffield. Porém, Arthur Tolkien contrai a febre reumática, que agravada pelo clima sulafricano o leva a óbito em 1895, deixando o filho com poucas recordações dele e fazendo com que a família tenha de voltar a morar definitivamente na Inglaterra numa má situação financeira.

Assim, os Tolkien vão morar numa casa de campo em Sarehole. Esta região deixa uma grande marca no escritor, que poderia estar expressa em suas obras nas verdes paisagens do Condado. Devido a morte de sua mãe por conta de diabetes, em 1904, tem sua educação confiada ao padre Francis Xavier Morgan que zelará pelos estudos de John levando-o a ingressar na Universidade de Oxford, inicialmente estudando Antiguidade clássica, porém, seu interesse e aptidão em filologia o levaram ao curso de Letras e Literatura inglesas, onde achou sua vocação no estudos graduando-se em 1915 com um First, nota mais alta do exame.

Quando estoura a Primeira Guerra Mundial, Tolkien se alista só após sua conclusão de graduação, incorporando- se ao $11^{\circ}$ batalhão do Lancashire Fusiliers como segundo-tenente. Participou na batalha do Somme, na França em 1916, que ficou conhecida pelo grande desperdício de vidas, devido a um erro de estratégia. Ao contrair a febre das trincheiras, ele retorna a Inglaterra onde passa mais de dezoito meses, praticamente todo o resto do período de guerra, entre melhoras e recaídas. (WHITE, 2013, p. 80)

Nesta época começam a germinar as primeiras sementes de $O$ Silmarillion, obra que encarna o desejo de Tolkien de criar uma mitologia inglesa, que para ele “...não tinha um conjunto significativo de lendas escritas que formassem uma mitologia completa”(WHITE, 2013, p.82), 
baseada principalmente em mitos nórdicos e valores cristãos. Mais um trauma da guerra é a perda de amigos de infância, Rob Gilson e G. B. Smith, companheiros e co-fundadores do Tea Club and Barrovian Society, clube de leitura da época colegial de Tolkien, perecem na guerra deixando apenas Cristopher Wiseman e Tolkien como remanescentes. Com o fim do conflito, depois de trabalhar como linguista no The New English Dictionary e como professor no Departamento de Letras da Universidade de Leeds, consegue a cadeira de Inglês Antigo em Oxford, já em 1925.

Tolkien se mostra um exímio professor, tendo uma boa reputação na academia, e participa de alguns grupos de leitura que teriam grande influência nas suas obras. Inicialmente o The Coalbiters, que tratava sobre as sagas islandesas, e depois o The Inklings, que segundo as paredes do pub favorito onde o grupo se encontrava: “...reuniam-se aqui para beber cerveja e discutir, entre outras coisas, os livros que estavam escrevendo." (WHITE, 2013, p. 124). Nessas reuniões, onde ele e outros acadêmicos compartilhavam e discutiam suas obras, trabalhou sua habilidade como contista, foi então que começou a tecer $O$ Hobbit e $O$ Senhor dos Anéis, que viriam a se tornar suas duas principais obras.

O Hobbit foi o livro que lançou Tolkien ao sucesso. A ideia para escrever a estória nasceu de uma anotação feita durante uma correção de provas, que dizia “...num buraco no chão vivia um hobbit” (WHITE, 2013, p. 21) e depois foi desenvolvida na forma de contos noturnos para seus filhos. Foi publicado em Londres, no ano de 1937, e nos EUA em 1938, tendo sucessivas edições. A obra fez tanto sucesso nos dois países que a editora pediu mais escritos sobre hobbits, Tolkien ofereceu O Silmarillion e outros escritos que ele já tinha, porém, não era o que a editora 
Cadernos de Clio, Curitiba, n. ${ }^{\circ}$ 4, 2013

queria. Assim ele se compromete a preparar uma nova estória, a qual dedicou treze anos da sua vida escrevendo e que nomeou $O$ Senhor dos Anéis.

Ele a escreveu principalmente durante os anos da Segunda Guerra Mundial, com sucessivos períodos de pausas e aceleramentos na escrita. Devido ao seu excessivo perfeccionismo, a narrativa só foi concluída em 1949. Após ter sérios problemas quanto a viabilidade de lançamento, o grande impasse era o desejo teimoso de Tolkien para que o lançamento fosse feito junto a $O$ Silmarillion e sem a divisão do livro que possuía mais de meio milhão de palavras, o que era uma jogada muito cara e perigosa para as editoras na época. Com o passar do tempo ele teve que reconsiderar sua posição e ceder, lançando a obra em três volumes entre 1954 e 1955, que foi muito bem recebida pelo público.

Em 1968, com a chegada conturbada do livro aos EUA, O Senhor dos Anéis já tinha mais de três milhões de exemplares vendidos e a vida de Tolkien havia mudado devido ao sucesso. Uma enxurrada de cartas de fãs invadia sua casa frequentemente, ele recebia ligações de pessoas no meio da madrugada que não levavam em conta a diferença de fuso horário, em um episódio alguns fãs chegaram até a acampar no gramado em frente a sua casa na esperança de vê-lo (WHITE, 2013, p. 208). O professor ficou muito feliz com o carinho dos fãs, mas começou a se sentir desconfortável com esse assédio e teve inclusive que mudar de endereço e tirar seu número da agenda telefônica.

Após o sucesso dos primeiros lançamentos, foi-lhe possibilitada a publicação de $O$ Silmarillion, porém, seu perfeccionismo e o desânimo causado tanto pelo envelhecimento quanto pela morte de sua esposa Edith 
Tolkien, falecida em 1971, o levaram a não concluí-lo antes da sua morte em 1973, aos 81 anos de idade. Seu filho, Cristopher Tolkien, foi o responsável pela organização, edição e publicação de seus escritos póstumos e é o atual detentor dos direitos sobre a obra do professor.

\section{Os primeiros passos na pesquisa}

Inicialmente, a escolha que precisa ser feita é quanto a que fonte utilizar, já que para quem quer pesquisar a obra de Tolkien há dois tipos de documento. O primeiro são os livros, escritos pelo próprio autor. O segundo seriam os filmes, que por terem sido lançados muito tempo após a morte de Tolkien, além de estarem presentes em outro contexto histórico, estariam sujeitos a possuir diferenças relacionadas a adaptação das páginas para as telas. Até o presente momento escolhi trabalhar com os livros já que estes se configuram como fontes mais vinculadas ao autor do que os filmes.

Um aspecto que chama a atenção na narrativa é o papel dos “orientais”, descritos como homens de pele escura vindos do leste e que lutam ao lado de Sauron, senhor do escuro e vilão em O Senhor dos Anéis. Eles possuem uma história de ódio com os habitantes da Terra Média devido a uma traição numa guerra passada contra o primeiro senhor do escuro, Morgoth.

Levando em conta o desejo de Tolkien de montar uma mitologia inglesa, as paisagens nas quais se desenrolam a história corresponderiam ao noroeste da Europa, fato atestado pelo próprio autor (WHITE, 2013, p. 189), esse leste fictício do qual vinham estes “orientais” poderia ser um 
paralelo ao Oriente real e as suas disputas com o Ocidente, ocorridas durante a Idade média. Outras teorias apontam que poderia ser uma menção ao leste socialista, porém, seguindo os mapas da Terra Média e sabendo da inspiração desta geopolítica, pelo menos geograficamente, esta hipótese não procederia.

Porém, uma obra deste tamanho está sempre sujeita a todo o tipo de interpretações, assim, no decorrer da pesquisa me deparei também com hipóteses de um possível viés racista na narrativa, que pediriam um aprofundamento maior de estudo, o qual eu não possuo agora já que esta pesquisa ainda se encontra em seu inicio. Segundo matérias, como algumas encontradas no blog Legio Victrix, este traço estaria bem representado na decadência dos númenorianos, homens de uma raça superior na estória, causada pela miscigenação com homens de raças inferiores e também na imagem dos elfos, raça antiga, superior, bela e sábia de cabelos longos e pele clara, que supostamente representaria o homem europeu.

O tempo histórico em que Tolkien estava inserido, junto a sua biografia, pode nos trazer um entendimento melhor sobre alguns aspectos de sua obra. Apesar das negações sustentadas por ele, paralelos indicam vários aspectos da sua vida refletidos na estória e nos personagens da Terra Média.

Como vimos anteriormente, Tolkien era uma espécie de ludita que teve de enfrentar os horrores do séc. XX, uma época onde as esperanças depositadas na tecnologia e nos ideais da Revolução Francesa foram destruídas devido, principalmente, a violência das duas Grandes Guerras. Estes acontecimentos teriam deixado em Tolkien grandes traumas resultantes, por exemplo, na perda da fé do autor no progresso e na tecnologia, 
o que o fez desenvolver uma aversão ao progresso, traço muito forte da sua época. (WHITE, 2013, p . 143)

Essa perda de fé estaria representada na obra em vários pontos. Primeiramente, poderíamos falar dos Orcs que se constituem numa raça deformada e decaída, supostamente descendentes de elfos corrompidos, que possuem uma ambição descontrolada por máquinas e coisas engenhosas. Eles sempre são mostrados como os inimigos dos homens ao lado do senhor do escuro, Sauron. Representariam expansão do progresso empreendida pelo Homem, que foi motivo para muitos dos conflitos do séc. XX, como a Primeira Guerra Mundial, na qual, como ressaltamos, o autor participou como combatente, assim como, a sede de progresso e a tecnologia que ele tanto repudiava após todas as suas experiências de vida. (WHITE, 2013, p.193)

Outro traço que simbolizaria ainda essa repulsa seria o papel da natureza nas suas obras, esta que no mundo real estava sendo engolida pelas máquinas sem ter como se defender. Na obra, ela é representada principalmente pelos Ents, ou pastores de árvores, e pelas águias que podem repreender, repudiar e reagir as ações de outros seres com que não concordem, se mostrando como uma grande ajuda na luta contra os exércitos inimigos.

Não podemos nos esquecer de um dos personagens principais, o hobbit Frodo, que sempre foi apontado como um reflexo de Tolkien. O modo de vida dos hobbits representava o estilo de vida predileto do escritor, calmo e aconchegante, num local verde e tranquilo chamado de Condado, lugar este que é apontado como um paralelo a zona rural de Sareho- 
Cadernos de Clio, Curitiba, n. ${ }^{\circ}$ 4, 2013

le em que a família Tolkien morou por um tempo e que trazia boas lembranças a sua memória.

A viagem de Frodo com a missão de destruir o anel, com todos os traumas, perigos e paisagens desoladas que o personagem tem de enfrentar, seriam um reflexo da experiência traumática do escritor nas trincheiras da Primeira Guerra, estando estas talvez expostas em trechos como este, onde poderia estar expressa a realidade de uma trincheira, onde os soldados tinham que dividir espaço com cadáveres muitas vezes já em estado avançado de putrefação:

“Nas poças, quando as velas estão acesas. Jazem em todas as poças, rostos pálidos, nas profundezas das águas escuras. Eu os vi: rostos repugnantes e maus, e rostos nobres e tristes. Muitos rostos altivos e belos, e ervas em seus cabelos prateados. Mas todos nojentos, podres, todos mortos.” (TOLKIEN, 2001, p. 659)

Outra questão típica do séc. XX abordada na obra é a verdadeira função da ciência e como esta deve ser utilizada. Este aspecto fica bem evidente em dois personagens que acabam se tornando antagônicos, os magos Gandalf e Saruman. Os dois são seres superiores e sábios, porém, Saruman que acreditava que só um grande poder poderia vencer o mal acaba fazendo o papel do corrompido, ao contrário de Gandalf. Este acredita que a forma de afastar o mal da Terra Média se encontra em meio às pessoas e as pequenas ações.

Poderíamos dizer com isso, que Tolkien estaria mostrando sua ideia sobre o que acreditava ser o verdadeiro uso da ciência, também baseado nas suas experiências particulares. No caso, o modo como os avanços tecnológicos, que eram tão esperados como ajuda, acabaram sendo utili- 


\section{Cadernos de Clio, Curitiba, n. ${ }^{\circ}$ 4, 2013}

zados como armas nos conflitos que o escritor assistiu no decorrer de sua vida.

Após todos estes possíveis paralelos, eu diria que Tolkien, como um homem do séc. XX que presenciou os dois maiores eventos bélicos da história da humanidade, teria utilizado a Idade Média como um refúgio a sua realidade e ao trauma deixado tanto nele quanto nas pessoas que viveram este momento.

Deste modo, voltamos mais uma vez a imagem inocente da Idade Média como motivo de sucesso deste período frente ao grande público. A fuga de uma realidade, onde o tão comentado vazio contemporâneo encontra saída numa representação de Medievo povoada por magos, guerreiros, grandes guerras e florestas habitadas por seres fantásticos. Esta representação ainda é uma grande cartada para a indústria do entretenimento, o que justificaria o sucesso prolongado de $O$ Senhor dos Anéis junto a tantas outras obras, filmes e séries com temática parecida.

\section{Conclusão Parcial}

Este trabalho ainda está em fase inicial. Como maior dificuldade encontrada, eu apontaria o difícil acesso a estudos acadêmicos sobre a obra de Tolkien, fato que pode ser justificado pelo receio que reinou por muito tempo na academia de estudar os produtos dos gêneros de ficção científica e fantasia, onde as obras tolkianas se encaixam, classificando-as como subgênero literário.

A própria literatura de Tolkien foi classificada como vazia frente a crítica marxista. Esta dizia que o grande sucesso de vendas era uma prova 
da falta de qualidade literária e a classificava como representante da literatura escapista que procurava evitar o engajamento político e a análise social. Porém, acredito que com a expansão dos temas a qual a História estuda, a obra de Tolkien está cada vez mais sendo explorada por acadêmicos.

Lenita Maria Rimoli Esteves, professora do departamento de linguística da Universidade de São Paulo (USP) e tradutora para português dos volumes de O Senhor dos Anéis e O Hobbit, em entrevista feita a Revista Brathair, quando perguntada sobre a tendência a desconsideração da obra de Tolkien e da literatura fantástica como objeto de estudo pela academia no Brasil e em todo o mundo afirma que:

[...] Hoje em dia, é perfeitamente aceitável você fazer uma pesquisa sobre novelas, músicas bregas ou qualquer outra produção de nossa cultura, justamente porque qualquer objeto de uma cultura merece (e deveria) ser estudado. Aliás, acho que faz mais sentido estudar o que é consumido pelas massas do que pesquisar um escritor que é lido por meia dúzia de cultos especialistas. (2005, p. 152)

Tanto pela sua qualidade, sua construção é quase impecável, quanto pelo fato de fazer tanto sucesso com o público, só o interesse que as pessoas mostram por narrativas deste tipo já se enquadraria como um motivo para estudo tanto na área em que estou quanto numa possível pesquisa sobre a receptividade da obra, além, é claro, do fato de ter feito pessoas que não tinham o hábito da leitura começarem a ler, apesar do grande volume das obras, o mundo criado por Tolkien se configura como um objeto legítimo de pesquisa.

Concluindo, considero que esta iniciativa de pesquisar tal temática está de acordo com toda uma nova tendência e preocupação da História 
das representações. Além disso, é uma pertinente possibilidade para estudar a maneira como o homem ocidental contemporâneo lida com um passado, aparentemente, tão distante e que desde o chamado renascimento tem sido legado apenas a um período entre a Antiguidade Clássica e a chamada Modernidade.

\section{Referências Bibliográficas:}

ALVARO, B.G.; PRATA, R.C. As ideias não correspondem aos fatos: Luzes sobre a Idade Média. Gnarus: Revista de História, Rio de Janeiro, ano 1, n.1, p.10-15, nov. 2012. Disponível em: http://issuu.com/gnarusrevistadehistoria/docs/gnarus1

CARPENTER, Humphrey; TOLKIEN, Cristopher. As cartas de J.R.R. Tolkien. Curitiba: Arte e Letra Editora, 2006.

CHARTIER, Roger. Introdução: por uma sociologia histórica das práticas culturais. In: História Cultural: entre práticas e representações. Rio de Janeiro: Bertrand Brasil, 1990.

ESTEVES, Lenita Maria Rimoli. Tolkien e a literatura Celto-Germânica. Entrevista realizada por CAMPOS, Luciana de; LANGER, Johnni. Brathair - Revista de Estudos Celtas e Germânicos, v. 5, n. 1, p. 151-154, 2005. Disponível em: http://dlm.fflch.usp.br/sites/dlm.fflch.usp.br/files/tolkien_e_a_literatura_celto.pdf

MACEDO, José Rivair. Introdução - Cinema e Idade Média: perspectivas de abordagem. In: ; MONGELLI, Lênia Márcia. (Org.). A Idade Média no cinema. São Paulo: Ateliê Editorial, 2009.

MONTEIRO, Maria do Rosário. O Senhor dos anéis: Mitos, História e Fantasia. Revista História, ano XXIV, Série III, p. 53-55, jan. 2003. Disponível em: http://www.fcsh.unl.pt/docentes/rmonteiro/pdf/LOTR_rmonteiro.pdf

TOLKIEN, J.R.R. O Hobbit. 3ª Ed. São Paulo: Martins Fontes, 2009.

O Senhor dos Anéis. Volume único. São Paulo: Martins Fontes, 2001.

O Silmarillion. 4ª Ed. São Paulo: Martins Fontes, 2009.

WHITE, Michael. J.R.R. Tolkien: O Senhor da fantasia. Rio de Janeiro: Darkside Books, 2013. 
Cadernos de Clio, Curitiba, n. ${ }^{\circ}$ 4, 2013

\section{Referências virtuais:}

SANTOS, A.A.R. A Idade Média Midiática. Disponível em: http://www.infonet.com.br/educacao//ler.asp?id=135720. Acesso em: 23 de Fevereiro de 2013.

CHARTIER, Roger. O Mundo como Representação. Disponível em: http://www.scielo.br/scielo.php?pid=S010340141991000100010\&script=sci_arttext Acesso em: 24 de Agosto de 2013

O Senhor dos Anéis e a Ariosofia. Disponível em: http://legiovictrix.blogspot.com.br/2012/12/o-senhor-dos-aneis-e-ariosofia.html. Acesso em: 26 de Fevereiro de 2013.

Tolkien: Mestre da Terra Média. Disponível em: http://legiovictrix.blogspot.com.br/2012/12/tolkien-mestre-da-terra-media.html. Acesso em: 26 de Fevereiro de 2013.

Tolkien e Idade Média. Disponível em: http://www.valinor.com.br/7206/. Acesso em: 16 de janeiro de 2012. 